\title{
Perencanaan Water Bus Double Hull Fiberglass Kapasitas Angkut 35 Orang
}

\author{
Amir Marasabessy ${ }^{1 *}$, Adella Hotnyda ${ }^{2}$, Ahmad Zayadi ${ }^{3}$ \\ ${ }^{1}$ Program Studi Teknik Perkapalan, Fakultas Teknik UPN “Veteran” Jakarta. \\ ${ }^{2}$ Program Studi Teknik Industri, Fakultas Teknik UPN "Veteran" Jakarta \\ ${ }^{3}$ Program Studi Teknik Mesin Faukltas Teknik Dan Sains Universitas Nasional, Jakarta 12520
}

*Korespondensi penulis: amir141161@gmail.com

\begin{abstract}
Abstrak. Water bus merupakan sarana transportasi angkutan penumpang pada pelayaran sungai atau danau yang saat ini dapat dikategorikan masih dalam jumlah yang belum signifikan jika dibandingkan dengan keberadaan sungai yang ada diwilayah Indonesia sehingga masih diperlukan pengembangan armada water bus berbahan fiberglass dan dari segi disain dapat dikatakan belum memaksimalkan faktor teknis dan ekonomis. Tujuan penelitian adalah desain prototipe model water bus double hull fiberglass yang memenuhi faktor teknis dan ekonomis. Metode yang digunakan pada tahapan preliminary disain adalah metode optomasi untuk menentukan ukuran utama kapal yang optimum berdasarkan data kapal pembanding yang telah diregister pada tahap basic disain dan optimation design approach untuk menghasilkan nilai optimum dari kriteria tertentu (objective function) dengan menentukan parameter yang harus dipenuhi dan menetapkan batasan-batasan (constraint) agar dapat meminimalkan engine power serta dapat digunakan untuk analisis tahapan basic disain serta perhitungan/gambar lines plan dan general arrangement menggunakan program. Hasil penelitian berupa prototipe model water bus double hull fiberglass tipe OBM yang dibuat dalam bentuk miniatur dengan ukuran Panjang $($ Loa $)=16,00 \mathrm{~m}$, Panjang $(\mathrm{Lwl})=14,61 \mathrm{~m}$, Lebar 5,26 m, Tinggi (H) 1,50 m dan sarat air (T) 0,70 m, kecepatan (V) 17 knot dan kapasitas engine $2 \times$ $175 \mathrm{HP}$.
\end{abstract}

Kata kunci: water bus, prototipe, double hull.

\begin{abstract}
Water bus is transfortation fasility of passengers on bringing on the river with now days can be classified which still unumber significantly if compared with river condition which there has been in Indonesia area then still needed establisment of water bus transfortation from the fibre glass material and from design corner can be said still unmaximal it is seen from design from technical and economic factors. Purpose of research is prototype design of water bus double hull fiberglass that fullfill technical and economical factor. The aim of this research is made prototype model of water bus double hull form fibre glass material which to full fill technical and economical factor. The method that's used on the step of preliminary design is optimalisation for defining the main demension of ship which is optimum based on ship comparing that has ben registered on the step of basic design and optimation design approach for resulting the optimum value with parameter defined which have to fullfill and set up the limits in order can me minimal engine power and also can be the step of basic design also the calculation of lines plan and general arrangement by using programming. The result of research is prototype model of water bus double hull from fiberglass material with OBM type which is built in miniatur shape with of $(\mathrm{Loa})=16.00 \mathrm{~m},(\mathrm{Lwl})=14.61$ $\mathrm{m}$, Width $5.26 \mathrm{~m},(\mathrm{H}) 1.50 \mathrm{~m}$ and water level $(\mathrm{T}) 0.70 \mathrm{~m}$, speed $17 \mathrm{knots}$ and engine capacity $2 \times 175 \mathrm{HP}$.
\end{abstract}

Keywords: water bus, prototype, double hull.

\section{PENDAHULUAN}

Water bus merupakan salah satu sarana transportasi angkutan penumpang dan barang melalui pelayaran sungai/danau. Keberadaan water bus yang beroperasi pada perairan 
sungai dan danau di wilayah Indonesia dapat dikategorikan masih dalam jumlah belum signifikan jika dibandingkan dengan keberadaan beberapa sungai yang terdapat di kotakota besar di Indonesia sehingga masih diperlukan pengembangan armada water bus, yang disesuaikan dengan rencana strategi nasional dalam pengembangan daerah parawisata di ber bagai wilayah Indonesia untuk pelayanan bagi para wisatawan mancanegara.

Penelitian yang telah dilakukan sebelumnya adalah perencanaan kapal ikan sederhana berbahan fiberglass, LPPM UPNVJ (2010) dan kajian desain dan produksi kapal patroli fiberglass, Disnaker BLKI Provinsi Banten (September 2015) serta kajian desain dan produksi kapal pesiar fiberglass, Disnaker BLKI Provinsi Banten (September 2015).

Pengadaan barang dan jasa berupa desain dan produksi water bus yang ada saat ini masih belum memaksimalkan faktor teknis dan ekonomis dalam hal penentuan besaran kecepatan dan tenaga motor induk. Selama ini besaran kecepatan dan tenaga motor induk nilainya dalam spesifikasi teknis selalu diberikan dengan nilai interval dan untuk menghindari sanksi denda maka galangan kapal pembangun dalam pemilihan tenaga motor induk selalu memilih lebih besar agar kecepatan kapal yang diperoleh sedikit lebih besar dari yang direncanakan. Akan tetapi kondisi ini yang mengakibatkan tidak ekonomis dalam perencanaan water bus karena dengan pemilihan motor induk yang lebih besar untuk pemenuhan kecepatan kapal tersebut membuat harga mesin induk menjadi lebih mahal, konsumsi bahan bakar menjadi besar dan dan secara teknis berpengaruh pada penempatan mesin induk di ruang kamar mesin.

Tujuan dari penelitian ini adalah Merencanakan water bus doble hull kapasitas angkut 35 orang berbahan fiberglass pada tahapan preliminarry design dengan mempertimbangkan faktor teknis dan ekonomis dengan membuat model prototipe dalam bentuk miniatur.

Dalam perencanaan, bentuk lambung (hull) akan dibuat berbeda dengan water bus lainnya dengan meminimalkan tahanan kapal melalui analisis tahanan untuk memperoleh kepastian besaran kecepatan kapal dan tenaga motor induk yang optimum serta analisis trim dan stabilitas untuk memastikan kondisi kapal saat beroperasi memiliki stabilitas yang baik. Untuk membuat prototipe water bus double hull fiberglass dalam bentuk miniatur maka dalam perencanaan akan dilakukan perhitungan dan pembuatan gambar rencana garis (lines plan), rencana umum (general arrangement).

\section{BAHAN DAN METODE}

\section{Bahan Kayu dan Gel coat}

Bahan yang digunakan untuk pembuatan model prototipe antara lain bahan kayu berupa melamin $3 \mathrm{~mm}$, ring kayu $2 \times 3 \mathrm{~cm}$ berikut bahan pendukung lainnya dan bahan gel coat berupa resin yukalac 157, pigment, cobalt, herosil dan katalis.

\section{Metode Optimasi Preliminary Desain}

Untuk mengurangi dan meminimalisasi ketidaksesuaian suatu desain terhadap owner requirement pada tahap preliminary desain perlu dilakukan studi dengan metode optimasi dalam menentukan ukuran utama kapal dan hull form yang optimal berdasarkan data kapal pembanding yang telah diregister pada tahap basic design [1] Sedangkan optimation design approach, sebagai suatu alternatif untuk menghasilkan nilai optimum dari kriteria tertentu (objective function) dengan menentukan parameter yang harus dipenuhi dan menetapkan batasan-batasan (constraint) agar dapat meminimalkan engine power serta dapat digunakan untuk analisis tahapan basic design [2].

\section{Tahapan Perencanaan}

Untuk melakukan desain prototype model water bus double hull berbahan fiberglass dengan kapasitas angkut 35 orang pada tahapan preliminary design maka sebagai tahap awal perencanaan dalam kegiatan penelitian ini adalah membuat perencanaan sesuai tahapan 1 hingga 4. Sebagaimana diperlihatkan pada gambar 1. 


\section{HASIL DAN PEMBAHASAN}

\section{Data Kapal Pembanding}

Tahap awal awal adalah proses pengolahan data dilakukan dengan menggunakan parameter pembanding/data kapal pembanding dari jenid water bus berbahan fibergelas, sesuai tabel 1.
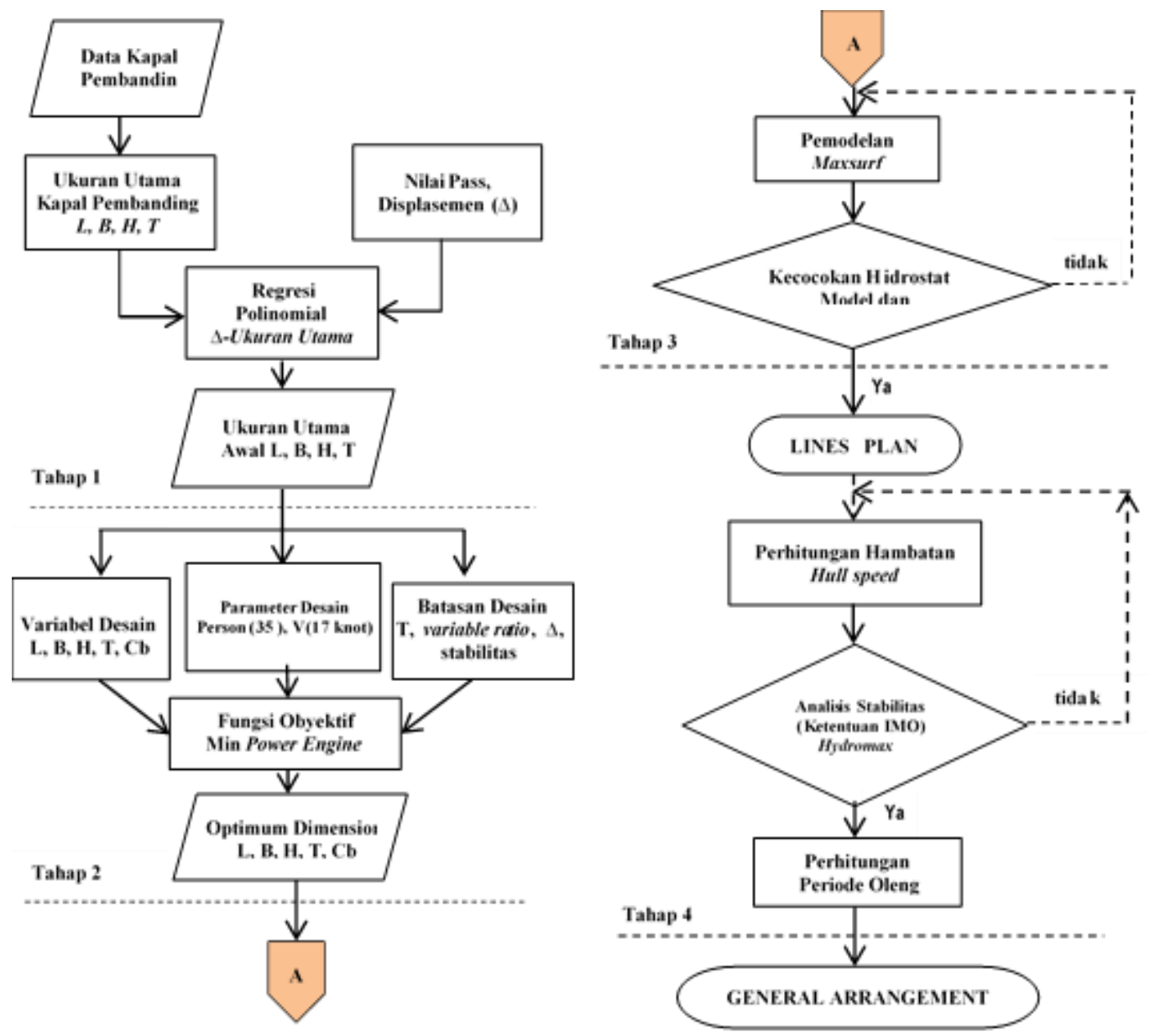

GAMBAR 1. Preliminary design tahap 1, 2, 3 dan 4

TABEL 1. Data kapal pembanding

\begin{tabular}{|c|c|c|c|c|c|c|c|c|}
\hline No. & Nama Kapal & $\begin{array}{c}\text { Passenger } \\
\text { (orang) }\end{array}$ & $\mathbf{L}(\mathbf{m})$ & $\mathbf{B}(\mathbf{m})$ & $\mathbf{H}(\mathbf{m})$ & $\mathbf{T}(\mathbf{m})$ & $\operatorname{FBR}(\mathrm{m})$ & V (knot) \\
\hline 1 & Clipper III & 49 & 14.400 & 5.600 & 1.700 & 0.700 & 1.000 & 28.000 \\
\hline 2 & Barracuda & 36 & 15.240 & 6.100 & 1.700 & 0.810 & 0.890 & 24.000 \\
\hline 3 & Wawahia & 48 & 17.100 & 6.400 & 1.750 & 0.800 & 0.950 & 28.000 \\
\hline 4 & Clipper V & 96 & 17.700 & 6.600 & 1.750 & 0.800 & 0.950 & 30.000 \\
\hline 5 & Crew change 16 & 32 & 16.100 & 5.600 & 1.500 & 0.650 & 0.850 & 28.000 \\
\hline 6 & Derektor 16 & 54 & 16.000 & 6.000 & 1.800 & 1.100 & 0.700 & 25.000 \\
\hline 7 & Clipper IV & 60 & 17.500 & 6.600 & 1.800 & 0.800 & 1.000 & 24.000 \\
\hline 8 & Orca 16 & 50 & 15.500 & 6.500 & 1.900 & 0.900 & 1.000 & 24.000 \\
\hline 9 & James Grant & 56 & 16.000 & 6.400 & 1.900 & 1.000 & 0.900 & 25.000 \\
\hline 10 & Fast launch & 60 & 15.000 & 6.300 & 1.800 & 0.800 & 1.000 & 25.000 \\
\hline \multicolumn{3}{|c|}{ Hasil Regresi } & 15.143 & 5.5245 & 1.514 & 0.702 & 0.81155 & 18.000175 \\
\hline
\end{tabular}

\section{Pengolahan Data}

Dari data-data pembanding water bus yang diperoleh dilapangan, selanjutnya dilakukan proses regresi polinomial antara ukuran utama kapal pembanding (L), (B), (H) dan (T) dengan jumlah passanger, dengan hasil sebagaimana diperlihatkan pada gambar 2 hingga $5[3]$. 


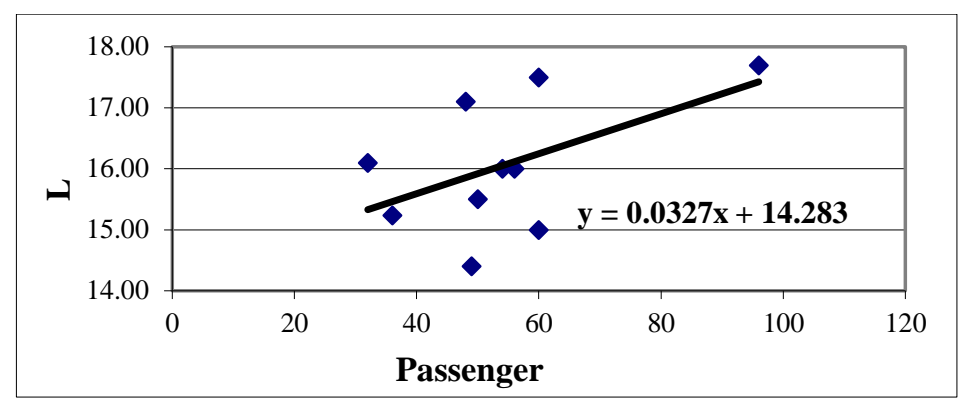

GAMBAR 2. Regresi polinomial ukuran utama kapal (L) terhadap nilai Passanger.

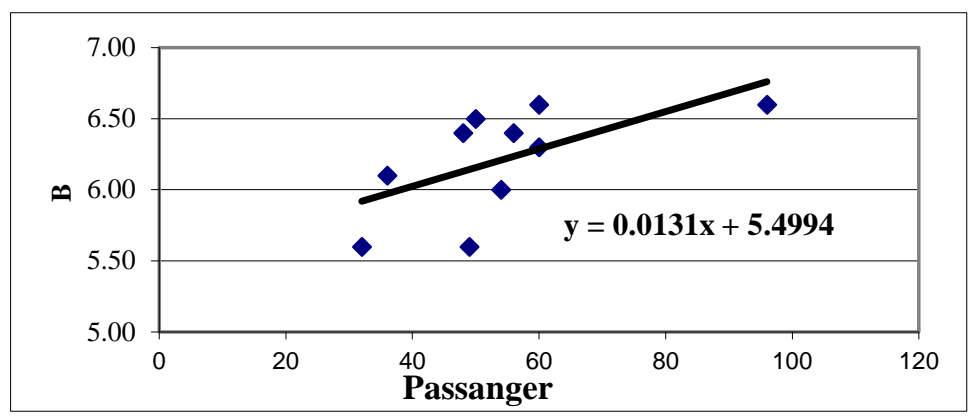

GAMBAR 3. Regresi polinomial ukuran utama kapal (B) terhadap nilai Passanger.

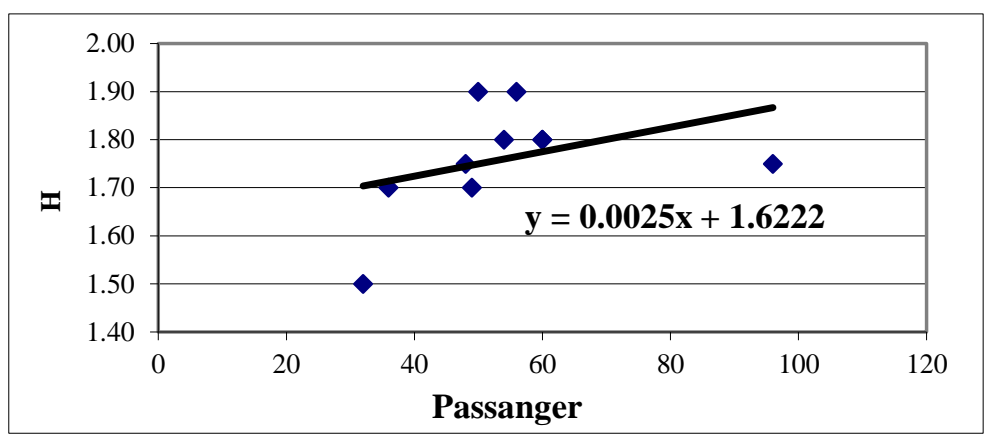

GAMBAR 4. Regresi polinomial ukuran utama kapal (H) terhadap nilai Passanger.

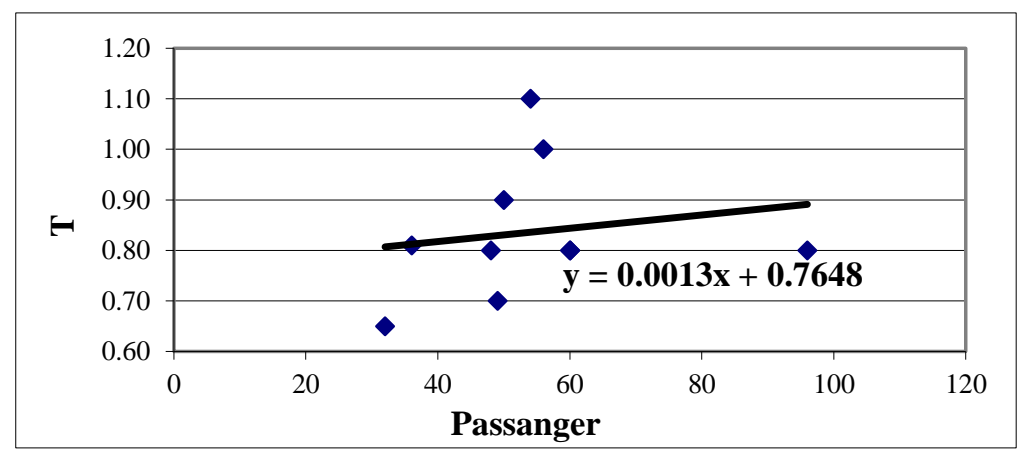

GAMBAR 5. Regresi polinomial ukuran utama kapal (T) terhadap nilai Passanger.

Nilai ukuran utama awal (initial value) variabel desain dari proses regresi polinomial yang didapat adalah:
- Panjang $(\mathrm{Lpp}) \quad=15.14 \quad[\mathrm{~m}]$
$-\operatorname{Lebar}(\mathrm{B}) \quad=5.52[\mathrm{~m}]$
- Tinggi $(\mathrm{H}) \quad=1.51[\mathrm{~m}]$
- Sarat $(\mathrm{T}) \quad=0.70 \quad[\mathrm{~m}]$
$-\mathrm{Cb} \quad=0.56$ (ditentukan) 


\section{Optimasi Variasi Ukuran Utama Kapal}

Berdasarkan variabel desain dari proses regresi polinomial dilanjut dengan menentukan variasi perbandingan ukuran utama kapal dengan 120 varian, maka dapat ditentukan nilai ukuran utama kapal yang optimumsebagai berikut ${ }^{[4]}$ :

- Panjang $(\mathrm{Lwl}) \quad=15.40[\mathrm{~m}]$

- Lebar $(\mathrm{B}) \quad=5.40[\mathrm{~m}]$

- Tinggi Deck $(\mathrm{H})=1.50[\mathrm{~m}]$

- Draft . Sarat $(\mathrm{T})=0.70[\mathrm{~m}]$

- Displacement $=13.20$ [ton]

- Coefficient block $(\mathrm{Cb})=0.55$

\section{Pemodelan Menggunakan Maxsurf}

Setelah mendapatkan set ukuran utama dari proses optimasi maka dilakukan pemodelan dengan menggunakan maxsurf modeler V8i sesuai gambar 5. Pemodelan hull mengacu pada lines plan kapal pembanding existing [5].

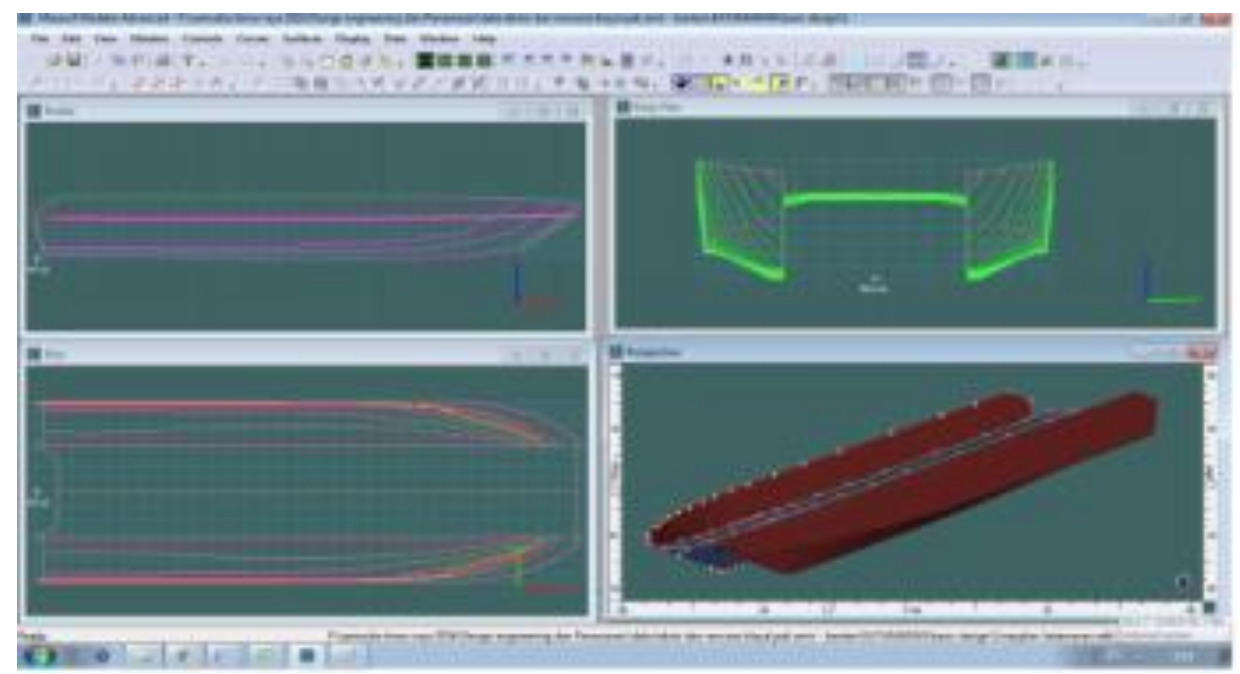

GAMBAR 6. Pemodelan menggunakan maxsurf modeler V8i.

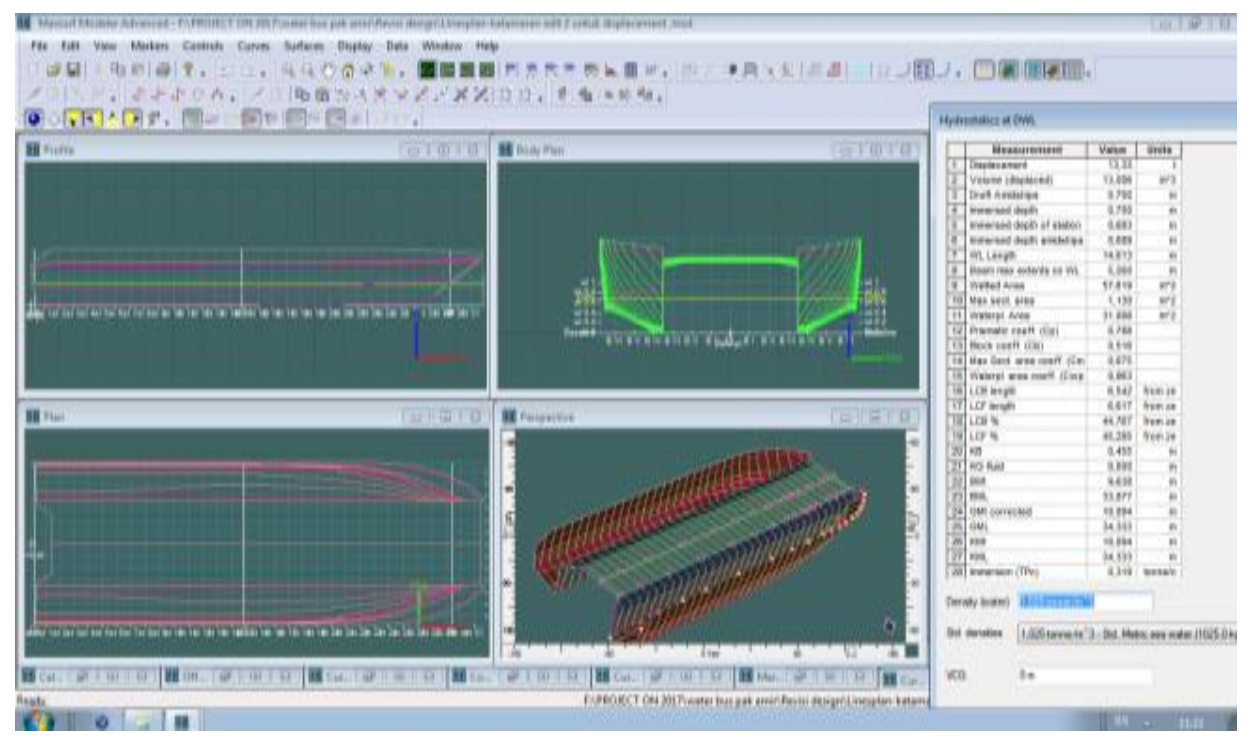

GAMBAR 7. Pengecekan kecocokan model calculate hydrostatic.

Kecocokan model dalam segi ukuran utama kapal dan karakteristik kapal dengan melihat pada item calculate hydrostatic pada Maxsurf, sesuai gambar 6, dan selanjutnya dilakukan per- bandingan nilai prosentase data kapal dari proses optimasi solver dengan data dari maxsurf, sesuai tabel 2 [6]. 
TABEL 2. Nilai hidrostatik dari model yang direncanakan.

\begin{tabular}{|c|c|c|c|}
\hline No & Parameter & Nilai & Satuan \\
\hline 1 & Displacement & 13,33 & $\mathrm{t}$ \\
\hline 2 & Volume (displaced) & 13,006 & $\mathrm{~m}^{\wedge} 3$ \\
\hline 3 & Draft Amidships & 0,700 & $\mathrm{~m}$ \\
\hline 4 & Immersed depth & 0,700 & $\mathrm{~m}$ \\
\hline 5 & Immersed depth of station with max area & 0,683 & $\mathrm{~m}$ \\
\hline 6 & Immersed depth amidships & 0,689 & $\mathrm{~m}$ \\
\hline 7 & WL Length & 14,613 & $\mathrm{~m}$ \\
\hline 8 & Beam max extents on WL & 5,260 & $\mathrm{~m}$ \\
\hline 9 & Wetted Area & 57,619 & $\mathrm{~m}^{\wedge} 2$ \\
\hline 10 & Max sect. area & 1,130 & $\mathrm{~m}^{\wedge} 2$ \\
\hline 11 & Waterpl. Area & 31,088 & $\mathrm{~m}^{\wedge} 2$ \\
\hline 12 & Prismatic coeff. $(\mathrm{Cp})$ & 0,788 & \\
\hline 13 & Block coeff. $(\mathrm{Cb})$ & 0,516 & \\
\hline 14 & Max Sect. area coeff. (Cm) & 0,675 & \\
\hline 15 & Waterpl. area coeff. (Cwp) & 0,863 & \\
\hline 16 & LCB length & 6,542 & from zero pt. (+ve fwd) $\mathrm{m}$ \\
\hline 17 & LCF length & 6,617 & from zero pt. (+ve fwd) $m$ \\
\hline 18 & LCB \% & 44,767 & from zero pt. (+ve fwd) \% Lwl \\
\hline 19 & LCF \% & 45,285 & from zero pt. (+ve fwd) \% Lwl \\
\hline 20 & KB & 0,455 & $\mathrm{~m}$ \\
\hline 21 & KG fluid & 0,000 & $\mathrm{~m}$ \\
\hline 22 & BMt & 9,638 & $\mathrm{~m}$ \\
\hline 23 & BML & 33,877 & $\mathrm{~m}$ \\
\hline 24 & GMt corrected & 10,094 & $\mathrm{~m}$ \\
\hline 25 & GML & 34,333 & $\mathrm{~m}$ \\
\hline 26 & KMt & 10,094 & $\mathrm{~m}$ \\
\hline 27 & KML & 34,333 & $\mathrm{~m}$ \\
\hline 28 & Immersion $(\mathrm{TPc})$ & 0,319 & tonne $/ \mathrm{cm}$ \\
\hline 29 & MTc & 0,313 & tonne.m \\
\hline 30 & RM at 1deg = GMt.Disp.sin(1) & 2,348 & tonne.m \\
\hline 31 & Length:Beam ratio & 5,931 & \\
\hline 32 & Beam:Draft ratio & 3,520 & \\
\hline 33 & Length: $\mathrm{Vol}^{\wedge} 0.333$ ratio & 6,214 & \\
\hline 34 & Precision & High & 123 stations \\
\hline
\end{tabular}

Dengan menginput data ukuran utama kapal berupa panjang kapal (Loa), (Lpp), lebar kapal (B), Tinggi geladak $(\mathrm{H})$, tinggi sarat $(\mathrm{T})$, coefisien blok dan frames space pada program maxsurf diperoleh gambar rencana garis (lines plan), sebagaimana yang di perlihatkan pada gambar 7 .

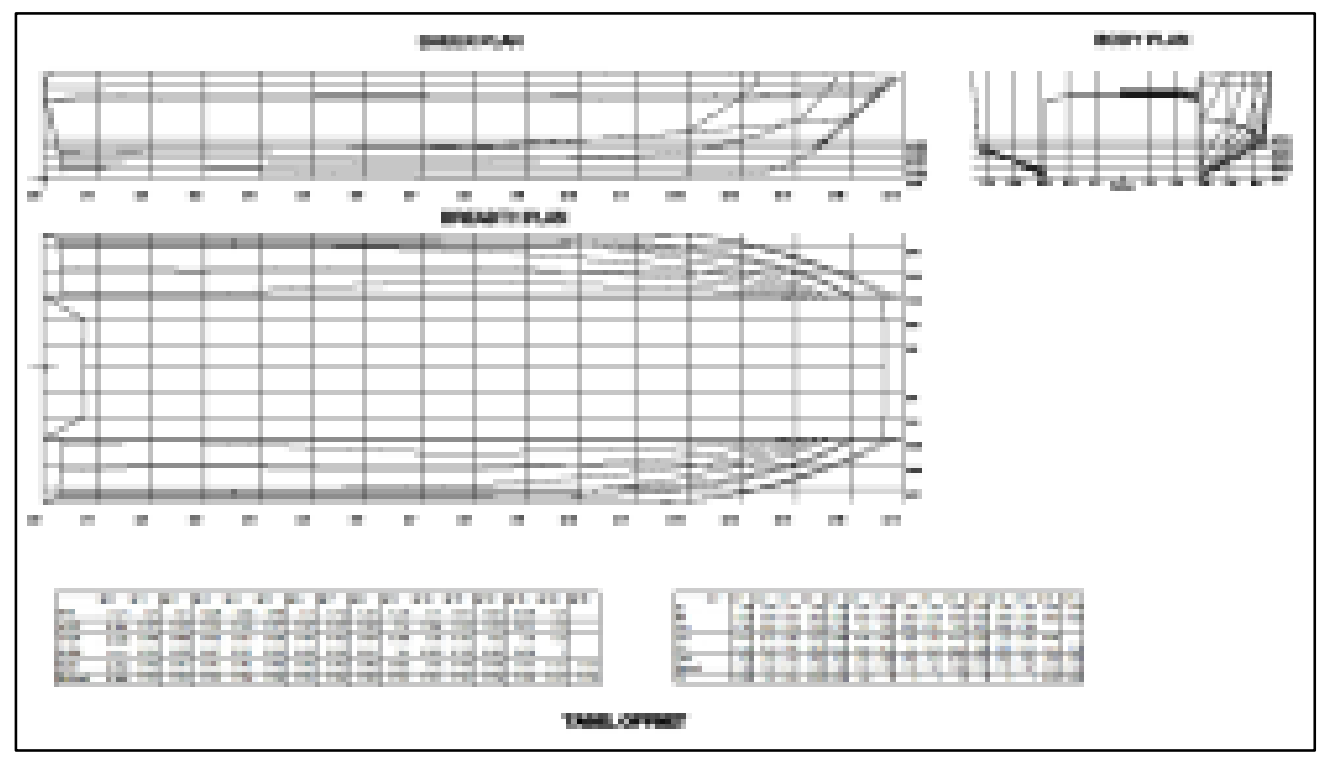

GAMBAR 8. Lines plan. 


\section{Analisis Data Model}

Untuk menentukan besarnya daya mesin yang dibutuhkan guna menggerakkan kapal dengan kecepatan tertentu dibutuhkan perhitungan tahanan lambung kapal berdasarkan data faktor bentuk dan nilai hidrostatis dari bentuk lambung kapal sesuai dengan rencana garis (lines plan) kapal [7].

Perhitungan hambatan kapal, sesuai dengan karakteristik dari bentuk badan kapal (hull form) water bus maka analisis hambatan menggunakan metode "Slender Body". Perhitungan hambatan menggunakan software "Hull Resistance" dengan input: Analysis speed $5 \mathrm{~s} / \mathrm{d} 18$ knot, sesuai gambar 8 [8].

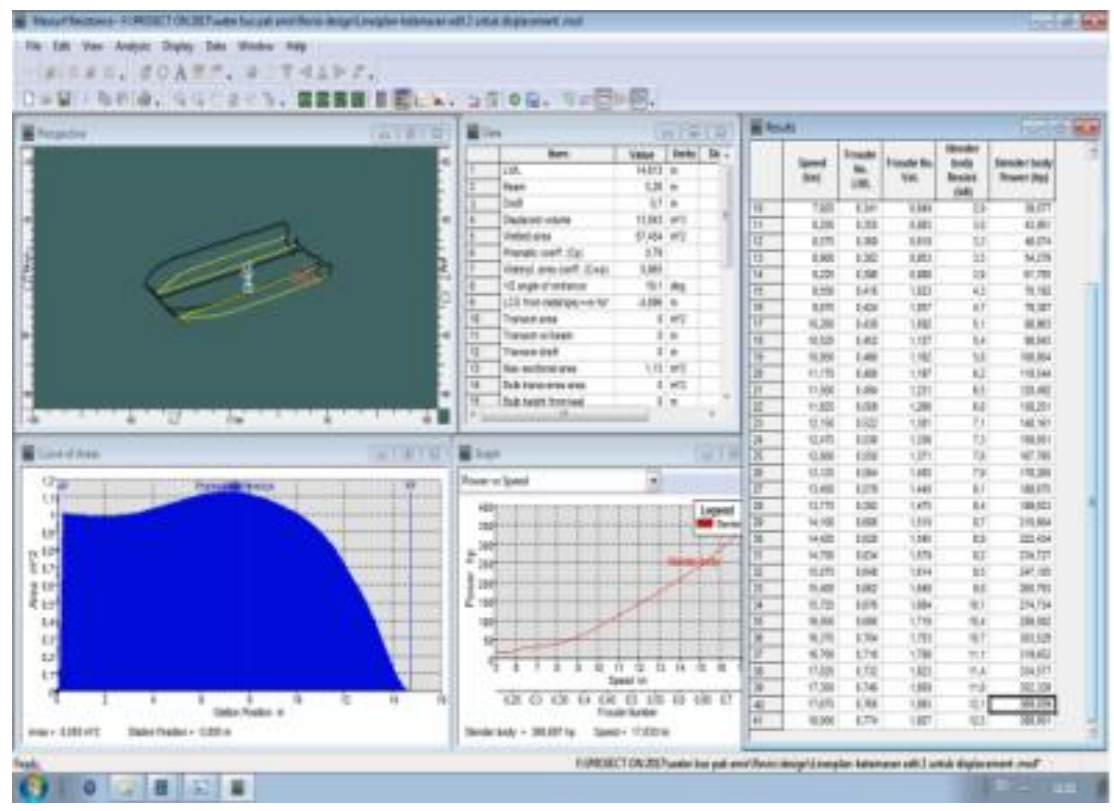

GAMBAR 9. Hasil running software hull resistance.

Adapun hasil perhitungan Resistance dan Power dengan menggunakan software maxsurf hull resistance, diperoleh tahanan sebesar $11.4 \mathrm{kN}$ pada kecepatan $17 \mathrm{knot}$ dengan power sebesar $335 \mathrm{Hp} \approx 350 \mathrm{Hp}$.

\section{Analisis Stabilitas Menggunakan Software Hydromax}

Sebelum melaksanakan analisis stabilitas awal pada kondisi $100 \%$ load, perlu menghitung karakteristik lambung kapal yag digambarkan dalam bentuk kurva dan data hydrostatik. Melalui software maxsurf stability advanced dan dari model yag dirancang melalui maxsurf modeller, di dapatkan data hidrostatik sesuai tabel 3.

Tabel 3. Data hidrostatik software maxsurf stability advanced.

\begin{tabular}{|l|r|}
\hline Draft Amidships m & 0,700 \\
\hline Displacement t & 13,36 \\
\hline Heel deg & 0,0 \\
\hline Draft at FP m & 0,700 \\
\hline Draft at AP m & 0,700 \\
\hline Draft at LCF m & 0,700 \\
\hline Trim (+ve by stern) m & 0,000 \\
\hline WL Length m & 14,613 \\
\hline Beam max extents on WL m & 5,260 \\
\hline Wetted Area m^2 & 57,431 \\
\hline Waterpl. Area m^2 & 31,086 \\
\hline Prismatic coeff. $(\mathrm{Cp})$ & 0,789 \\
\hline Block coeff. (Cb) & 0,517 \\
\hline Max Sect. area coeff. (Cm) & 0,673 \\
\hline Waterpl. area coeff. (Cwp) & 0,863 \\
\hline
\end{tabular}

\begin{tabular}{|l|r|}
\hline KB m & 0,455 \\
\hline KG m & 0,700 \\
\hline BMt m & 9,611 \\
\hline BML m & 33,865 \\
\hline GMt m & 9,366 \\
\hline GML m & 33,620 \\
\hline KMt m & 10,066 \\
\hline KML m & 34,320 \\
\hline Immersion (TPc) tonne/cm & 0,319 \\
\hline MTc tonne.m & 0,307 \\
\hline RM at 1deg = GMt.Disp.sin(1) tonne.m & 2,183 \\
\hline Max deck inclination deg & 0,0000 \\
\hline Trim angle (+ve by stern) deg & 0,0000 \\
\hline LCF from zero pt. (+ve fwd) $\mathrm{m}$ & 6,596 \\
\hline LCB from zero pt. (+ve fwd) $\mathrm{m}$ & 6,527 \\
\hline
\end{tabular}


Berdasarkan perhitungan dari data hidrostatik, selanjutnya dilakukan analisis stabilitas awal model kapal pada kodisi $100 \%$ load melalui perhitungan sesuai tabel 4 dan grafik 5 [9].

Tabel 4. Analisis stabilitas awal model kapal pada kodisi $100 \%$ load.

\begin{tabular}{|l|l|l|l|l|}
\hline Heel to Starboard deg & \multicolumn{1}{|c|}{$\mathbf{0 . 0}$} & \multicolumn{1}{c|}{$\mathbf{1 0 . 0}$} & \multicolumn{1}{c|}{$\mathbf{2 0 . 0}$} & \multicolumn{1}{c|}{$\mathbf{3 0 . 0}$} \\
\hline GZ m & 0.000 & 1.464 & 1.859 & 1.754 \\
\hline Area under GZ curve from zero heel m.deg & 0.0000 & 7.9451 & 25.3451 & 43.5486 \\
\hline Displacement & 13.00 & 13.00 & 13.00 & 13.00 \\
\hline Draft at FP m & 0.699 & 0.612 & 0.345 & -0.071 \\
\hline Draft at AP m & 0.680 & 0.651 & 0.347 & -0.099 \\
\hline WL Length m & 14.609 & 14.920 & 14.948 & 14.664 \\
\hline Beam max extents on WL m & 5.256 & 4.818 & 2.747 & 2.726 \\
\hline Wetted Area m^2 & 56.825 & 50.790 & 40.298 & 40.295 \\
\hline Waterpl. Area m $^{\wedge}$ & 31.040 & 25.158 & 18.589 & 20.419 \\
\hline Prismatic coeff. $(\mathrm{Cp})$ & 0.786 & 0.792 & 0.809 & 0.819 \\
\hline Block coeff. (Cb) & 0.507 & 0.481 & 0.711 & 0.697 \\
\hline LCB from zero pt. (+ve fwd) m & 6.570 & 6.569 & 6.571 & 6.572 \\
\hline LCF from zero pt. (+ve fwd) m & 6.594 & 6.762 & 6.984 & 7.016 \\
\hline Max deck inclination deg & 0.0740 & 10.0011 & 20.0000 & 30.0001 \\
\hline Trim angle (+ve by stern) deg & -0.0740 & 0.1522 & 0.0097 & -0.1083 \\
\hline
\end{tabular}

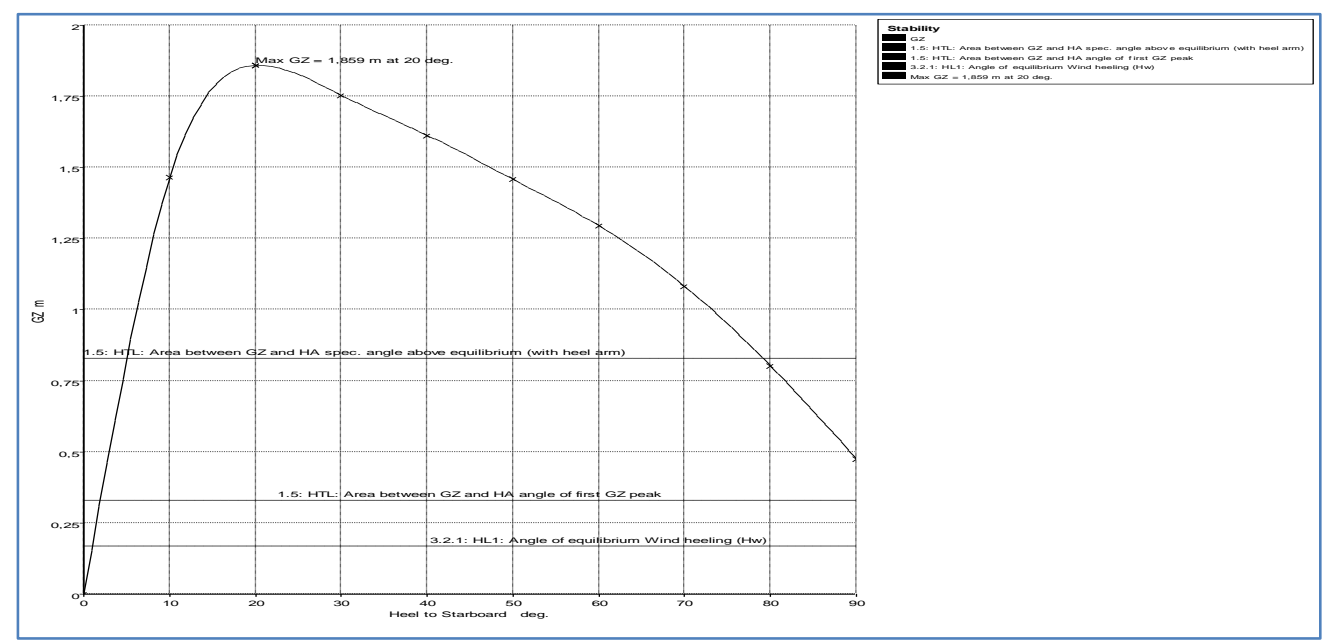

GAMBAR 10. Stabilatas awal model kapal pada kondisi $100 \%$ load.

Pada kondisi $100 \%$ load (displacement) stabilitas memenuhi yang disyaratkan oleh IMO yaitu luasan dibawah kurva stabilitas antara sudut oleng $0^{\circ}$ sampai dengan $30^{\circ}$ sebesar 25.35 m.deg yaitu lebih dari minimal yang disyaratkan sebesar 4.72 m.deg. Untuk kriteria sudut GZ maksimum juga terpenuhi dimana persyaratan yang harus dipenuhi yaitu minimal $10^{\circ}$, hasil yang didapatkan sudut GZ sebesar $20^{\circ}[10]$.

\section{Analisis periode rolling pada stabilitas awal}

Kehandalan kapal dipengaruhi stabilitas yang ditentukan oleh faktor periode oleng. Periode oleng adalah waktu yang dibutuhkan kapal untuk kembali tegak setelah kapal miring karena gaya yang bekerja padanya. Dalam perhitungan periode oleng menggunakan hubungan:

$T=\frac{2 \cdot \pi \cdot k}{\sqrt{g \cdot G M}}$, mengacu pada gambar 6

dimana:

$\mathrm{T}=$ periode oleng $[\mathrm{s}]$

$\mathrm{g} \quad=$ gravitasi bumi $\quad\left[\mathrm{m} / \mathrm{s}^{2}\right]$

$\mathrm{GM}=$ panjang metacenter $[\mathrm{m}]$

$\mathrm{k}$ = suatu konstanta (perbandingan inersia dengan massa kapal, nilainya antara 14-20 


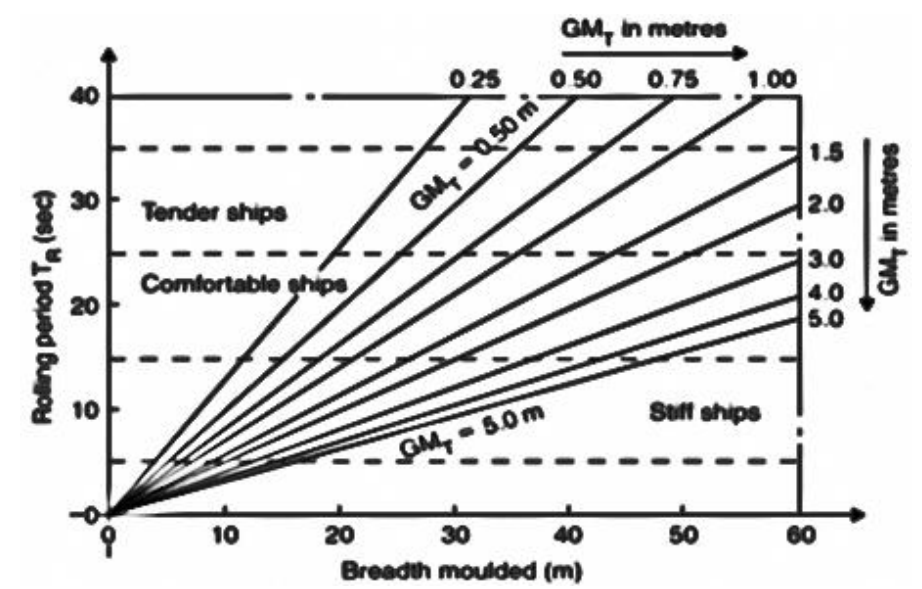

GAMBAR 11. Rolling Periode [11].

Hasil perhitungan periode oleng:

$\mathrm{g}=9,81\left[\mathrm{~m} / \mathrm{s}^{2}\right]$

$\mathrm{GM}=6.89[\mathrm{~m}]$ (dari data hidrostatik model maxsurf)

$\mathrm{k}=$ diambil 20

maka: $T=\frac{2 . \pi \cdot k}{\sqrt{g \cdot G M}}=\frac{2 \times 3,14 \times 20}{\sqrt{9,81 \times 6.89}}$

$$
=15.485 \mathrm{~s}
$$

Periode oleng kapal antara 30-35 (s) maka dapat dikatakan kapal mempunyai stabilitas yang tidak kaku (tender) dan mengakibatkan ketidak nyamanan pada gerak kapal dan penumpang. Sedangkan periode kapal dibawah 8 (s) maka dapat dikatakan kapal mempunyai stabilitas yang kaku (stiff) yang juga mengakibatkan ketidak nyamanan pada gerak kapal dan penumpang karena oleng kapal terlalu cepat. Untuk kapal yang mempunyai periode oleng yang baik berkisar antara 12-18 (s) (Barras dan Derret, 2006). Maka dapat dikatakan Kapal pesiar ini mempunyai stabilitas yang baik dengan nilai periode oleng sebesar 15.485 second.

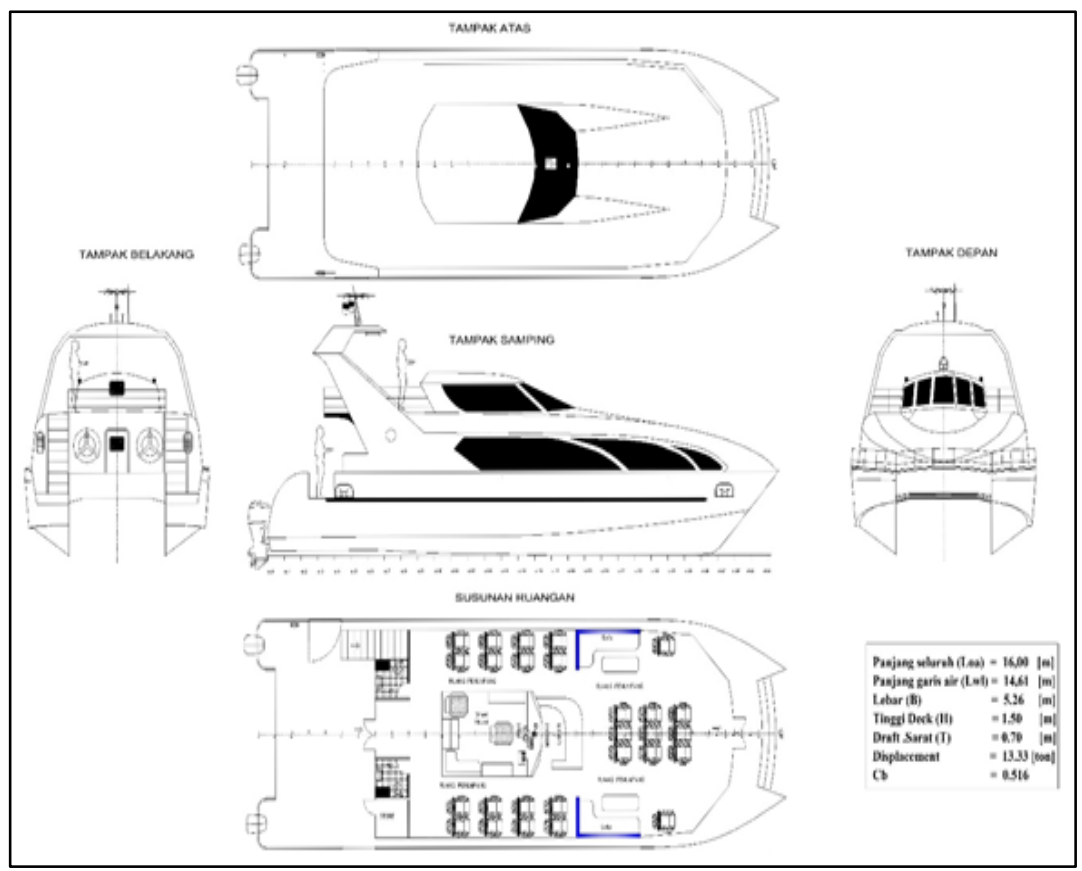

GAMBAR 12. General arrangement water bus double hull.

General arrangement water bus berbahan fiberglass sebagaimana yang diperlihatkan pada gambar 8. merupakan rencana penempatan ruangan/akomodasi, perlengkapan kapal, 
perlengkapan keselamatan, perlengkapan navigasi/komunikasi, perlengkapan tambat disesuaikan dengan standar (IMO) [12] yakni:

a. Ruangan/akomodasi

- Store untuk penyimpanan peralatan (tali, pompa, smoke signal dan lain lain)

- Ruang penumpang, d1tempatkan seat dengan jumlah 35 unit.

- Area genset dan area mesin.

- Area geladak navigasi.

- Area deck terbuka di top deck.

b. Susunan tangki

- Tanki bahan bakar, kapasitas 2 x 2000 liter terletak didaerah buritan (dibawah deck).

- Tangki air tawar kapasitas 2 x 2000 liter terletak di daerah buritan (dibawah deck) type fixed

c. Perlengkapan tambat

Perlengkapan tambat yang teridiri dari jangkar galvanize $15 \mathrm{~kg}$, ditempatkan di daerah haluan. Tali jangkar nylon dia. $15 \mathrm{~mm}$ panjang 100 meter, ditempatkan di daerah store serta 4 set bolder dan cleats stainless steel $10 \mathrm{inch}$.

d. Peralatan Kemudi

Sistem Steering Wheel Hydraulic yang dihubungkan dengan Outboard engine di daerah buritan. Steering wheel diletakkan di daerah anjungan (geladak navigasi) dimana penempatannya disesuaikan agar mudah dioperasikan.

d. Peralatan keselamatan

Perlengkapan keselamatan yang terdiri dari life jacket, life buoy, botol pemadam type busa $2 \mathrm{~kg}$, kotak obat, smoke signal.

e. Peralatan navigasi/komunikasi

Perlengkapan navigasi/komunikasi yang terdiri dari marine compas, VHF marine radio serta marine GPS dan echosounder.

\section{KESIMPULAN}

Berdasarkan hasil perhitungan rancangan pada tahapan preliminary design maka dapat dibuat spesifikasi rancangan Water Bus Double Hull Kapasitas Angkut 35 Orang berdasarkan Hasil perhitungan ukuran pokok water bus panjang seluruh (Loa) 16.00 [m], Panjang Garis Air (Lwl) 14.61 [m], lebar kapal (B) 5.26 [m], Tinggi Geladak (H): 1.50 [m], Tinggi Sarat (T) 0.70 [m], Coefficient Block (Cb) 0.516, Coefficient Prismatik (Cp) 0.788. Sedangkan coefficient midship $(\mathrm{Cm}) 0.675$, coefficient water line $(\mathrm{Cw}) 0.863$, Displacement $(\underline{\Lambda}) 13.3$ [ton]. Kapasitas angkut 35 orang. Kemudian mesin penggerak $2 \mathrm{x}$ $175 \mathrm{Hp}$ (marine use)-OBM. Bahan/material fiberglass. Stabilitas KB 0.455 [m], KG 0.70 [m], TPc 0.319 [t/cm], MTc 0.313 [t.m], GM 10.094 [m].

\section{UCAPAN TERIMA KASIH}

Ucapan terima kasih disampaikan kepada Direktorat Riset dan Pengabdian Masyarakat Direktorat Jenderal Penguatan Riset dan Pengembangan Kementrian Riset, Teknologi, dan Pendidikan Tinggi yang telah mendanai penelitian ini untuk periode 2 tahun 2017 s/d 2018. Ucapan terima kasih juga disampaikan kepada PT. Pruskoneo Kadarusman dan CV.Cisanggarung Putra Mandiri yang telah membantu memberikan data prototype water bus.

\section{DAFTAR PUSTAKA}

[1] Hadi, E.S. dan Zain, A., 2011, Preliminary Desain Hull Form Kapal General Cargo untuk Pelayaran Jakarta-Makasar dengan Menggunakan Metode Pendekatan 
Deterministic, Jurnal Kapal-Vol. 8., No.1, Februari, ISSN: 1829-8370, Universitas Diponegoro, Semarang.

[2] Ping, Z., De-xiang, Z., Wen-hao, L., 2008, "Parametric Approach to Design of Hull Forms", Elsevier, Journal of Hydrodynamic, 20(6): 804-810.

[3] Ventura, M., 2008, "Ship Design I", Ship Design Lecture's Notes, Naval Architecture and Marine Engineering, Instituto Superior Técnico, Lisbon, Portugal.

[4] Harris, J. and Morrison, I., 1998, Moduli of curves, Bulletin (New Series) Of the American Mathematical Society, Springer, New York, ISBN 0-387- 98438-0

[5] Hendra, S.T., 2000, Dasar Pemprograman Visual Basic, Modul 1: Pengenalan Visual Basic, Universitas Gunadarma.

[6] Maxsurf Automation Manual, Formation Design Systems Pty Ltd 1984 - 2010

[7] Parsons, M.G., 2001, "Parametric Design”, Univ. of Michigan, Dept. of Naval Architecture and Marine Engineering.

[8] Molland, A.F., Turnock, R.S. and Hudson, D.A., 2011, "Ship Resistance and Propulsion: Practical Estimation of Propulsive Power", Cambridge University Press.

[9] Couser, Patrick, 2003, “A Software Developer's Perspective Of Stability Criteria”, 8th International Conference on the Stability of Ships and Ocean Vehicles, Madrid, Spain.

[10] IMO, 1974, Intact Stability Code, Intact Stability for All Types of Ships Covered by IMO Instruments. London, UK: IMO.

[11] Barras, C.B. and Derret, D.R., 2006, "Ship Stability for Master \& Mates", sixth edition. London

[12] International Maritime Organization (IMO), International Convention on Load Lines (ICLL), 1966, as amended. 